\title{
Acute intracranial epidural haematoma in a basketball player: a case report
}

\author{
Roberto Datti MD, Salvatore Luca Gentile MD and Roberto Pisani MD \\ Institute of Neurosurgery, University of Genoa, Ospedale San Martino, Pad. 2, Viale Benedetto XV, No 10, 16132 \\ Genoa, Italy
}

\begin{abstract}
A 35-year-old basketball player suffered a serious double head injury during a match. An acute left temporal epidural haematoma, which necessitated surgical drainage, developed. The exceptional circumstances of the trauma are discussed and the literature concerning basketball-related injuries is reviewed.
\end{abstract}

Keywords: haematoma, epidural haematoma, basketball, sport, sport injury

The occurrence of an acute intracranial epidural haematoma during a basketball game is exceptional. In fact, we have not found any literature dicussing such an accident during a basketball match.

\section{Case report}

The patient, a 35-year-old player (guard), was running with a team mate to regain the ball. At the moment of impact the trunk and legs of both players were bent. The patient suffered his first serious head injury by the forceful collision of his left temporal region against his team mate's forehead, followed by an immediate loss of consciousness. Unconscious, he then fell awkwardly to the floor hitting his left occipital region violently against the ground, thus sustaining his second head trauma. Although regaining consciousness 40 seconds later, the patient was confused and after 20 minutes vomited. On admission to our Institute, the patient presented with retrograde amnesia, inability to concentrate and a Glasgow Coma Scale Score of 14. Skull radiography showed a single left occipital fracture transversing the sulcus transversus. Two hours after the injury a CT scan was carried out, which revealed a left temporal epidural haematoma (Figure 1). The patient's haematoma was then evacuated via a left temporal parietal craniotomy. At surgery, a double vertical fracture of the temporal and parietal bones was found, which had not been appreciated at radiography. The postoperative course was uneventful and 10 days later the patient, in a satisfactory condition, was

Address for correspondence: Dr R. Datti, Institute of Neurosurgery, University of Genoa, Ospedale San Martino, Pad. 2, Viale Benedetto XV, No 10, 16132 Genoa, Italy

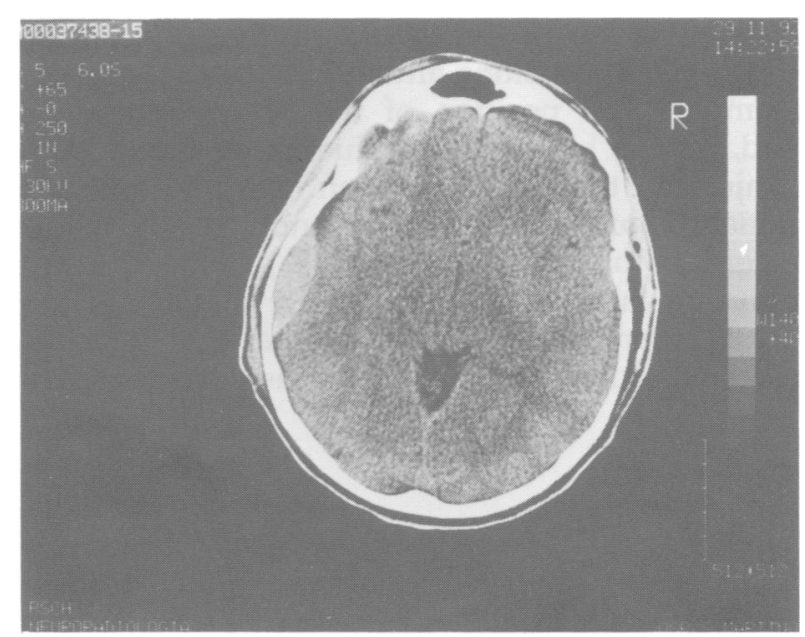

Figure 1. CT scan showing a left temporal epidural haematoma

discharged under barbiturate protection. A postoperative CT control demonstrated the successfully evacuated haematoma. No epileptic seizures occurred during the following year.

\section{Discussion}

According to statistics compiled by the US National Center for Catastrophic Sports Injury Research, the sports with the highest incidence of catastrophic head or neck injuries include football; gymnastics; ice hockey and wrestling. Other sports in which there is a significant possibility of head injury include the pole-vault; baseball; horse racing; motorcycle, automobile and boat racing; sky diving; boxing; martial arts and rugby ${ }^{1}$. Golf, shooting, climbing and skating were also reported ${ }^{2}$.

Basketball has traditionally been regarded as having a low risk of nervous system injuries even if it has the highest frequency of college non-collision sport injuries ${ }^{3}$. The only report which we found concerning a potentially catastrophic head injury, during a basketball game, which evolved into an acute intracranial haematoma, concerned a 17-yearold boy who was struck on the left side of the head by a ball rebounding off the metal rim of the basket. The boy underwent frontal-temporal craniotomy in order to evacuate the acute subdural haematoma as well as 
a large intratemporal haematoma: this report was detailed by specific theoretical biodynamics ${ }^{4}$. Common injury sites in basketball, the most frequent of which concern the lower extremities ${ }^{5,6}$, are the foot, ankle, knee, back and hand. The most serious injuries usually affect the ankle and knee ${ }^{7}$. Whilst ankle injuries occur indifferently in both sexes, there is a female prevalence for knee injuries ${ }^{8}$. Sportrelated nervous system injuries are fairly uncommon in basketball, generally comprising $10-20 \%$ of the total injuries ${ }^{3}$. Amongst these we have found a report of an unusual acute epidural lumbar haematoma due to a bilateral fracture of the fifth lumbar lamina after an awkward landing from a jump in a 22-year-old man 9 . In professional basketball, $12 \%$ of injuries are to the head and face and are generally not severe, the worst being a concussion without loss of consciousness whilst contusions and lacerations are the most common ${ }^{7}$. The position of the player (guard, forward, centre) has a slight influence on the incidence of injuries ${ }^{6}$, the centre position being the one most frequently subjected to injury and with the highest percentage of head injuries $(23 \%)^{7}$. Age is also an important factor, the younger the player the more he/she is prone to injury. In the case which we described, the dynamics of the accident were unusual: rarely does a severe double head injury cause a skull fracture at two sites of impact (in this case parietal and occipital), and induce immediate loss of consciousness after the first trauma. These particular dynamics played an important role in the development of this potentially fatal injury.

\section{References}

1 Cantu RC. Cerebral concussion in sport. Sp Med 1992; 14: 64-74.

2 Lindsay KW, McLatchie G, Jennett B. Serious head injury in sport. Br Med J 1980; 281: 789-91.

3 Lehman LB. Nervous system sports-related injuries. Am J Sports Med 1987; 15: 494-99.

4 Tudor RB. Acute subdural hematoma following a blow from a basketball. Am J Sports Med 1979; 7: 136.

5 Engel J, Baharav U, Modan M. Epidemiology of basketball injuries. Harefuah 1990; 119 (5-6): 121-124. (Summary).

6 Pfeifer JP, Gast W, Orringer W. Traumatology and athletic injuries in basketball. Sportverletz Sportschaden 1992; 6: 91-100.

7 Henry JH, Lareau B, Neigut D. The injury rate in professional basketball. Am J Sports Med 1982; 10: 16-18.

8 Zelisko JA, Noble B, Porter M. A comparison of men's and women's professional basketball injuries. Am J Sports Med 1982; 10: $297-99$.

9 Garr WP, Van Patten PK. Fractures of the lumbar lamina with epidural hematoma simulating herniation of a disc. J Bone Joint Surg 1989; 5: 771-72. 